\title{
Mortality of workers exposed to dieldrin and aldrin: a retrospective cohort study
}

\author{
Geert de Jong, Gerard M H Swaen, Joseph J M Slangen
}

\begin{abstract}
Objective-To investigate the occurrence of long term health effects in humans exposed to aldrin and dieldrin, with an update of an earlier retrospective cohort mortality study.

Methods-A group of 570 workers employed between 1 January 1954 and 1 January 1970 either in a production or formulation plant were followed up for mortality until 1 January 1993. There were extensive industrial hygiene data available and biological monitoring data of aldrin and dieldrin for most of the workers. From these data individual estimates were made of the total intake of dieldrin. A total number of 2539.37 person-years at risk was added to the original study.

Results-118 deaths were observed compared with 156 expected. No increase in mortality from liver cancer was found. However, there was an excess in mortality from rectal cancer. This excess was inversely related to the dose gradient. An analysis by job title did not show any excess cancer in any particular job.

Conclusion-The study does not support a carcinogenic effect of dieldrin and aldrin in humans.
\end{abstract}

(Occup Environ Med 1997;54:702-707)

Keywords: cancer risk; aldrin; dieldrin; epidemiology; occupational exposure

Aldrin and dieldrin are chlorinated hydrocarbon pesticides that were extensively used as insecticides in agriculture and in the treatment of seeds up to the early 1970 s. $^{12}$ Long term studies in mice have provided some support for a carcinogenic effect from these agents.

After that period their use became more and more restricted to specific applications such as termite control. ${ }^{3}$ Aldrin and dieldrin are readily absorbed after inhalation, ${ }^{4}$ ingestion, ${ }^{2}$ and after skin contact. ${ }^{5}$ In the occupational setting skin contact is thought to be the most important route of exposure. ${ }^{5}$ After intake aldrin is rapidly converted into dieldrin mainly by the liver. Dieldrin is mainly stored in adipose tissue. ${ }^{6}$ The biological half life in humans has been estimated to be 266 days. ${ }^{5}$

Apart from acute and subchronic effects there is some concern regarding possible long term effects of exposures to dieldrin and aldrin. Chronic oral studies in mice have shown increased incidences of benign and malignant liver tumours. ${ }^{7}$ The International Agency for
Research on Cancer (IARC) classified the evidence for carcinogenicity to animals as limited. The Joint Meeting on Pesticides Residues (JMPR) established an acceptable daily intake (ADI) for aldrin and dieldrin combined of 0.1 $\mu \mathrm{g} / \mathrm{kg}$ body weight in 1966 and 1977 based on the conclusion that aldrin and dieldrin are not human carcinogens. ${ }^{2}$ There are mainly two situations in which humans were exposed to aldrin and dieldrin. The first was in manufacturing and formulating these agents. The second was in their application as insecticides in the field or in dwellings. These insecticides are, as far as we know, currently not manufactured or used anywhere in the world.

Two production sites of aldrin and dieldrin have been the subject of epidemiological investigations of possible long term health effects. Ditraglia et al carried out a retrospective cohort study of four organochlorine pesticide manufacturing plants in the United States. ${ }^{8}$ One of these plants manufactured aldrin, dieldrin, and endrin from 1951 up to the early 1970s. A total of 1155 workers had been employed at this plant for at least six months before January 1964 and were followed up for mortality until 31 December 1976. The total mortality of this group was lower than expected, based on the mortality of the general population. Although the investigators concluded that no specific risk of cancer associated with employment at certain organochlorine pesticide manufacturing plants could be identified, there were several cancer sites that were stated to deserve further examination. These cancer sites for the workers in the aldrin, dieldrin, and endrin plants were oesophagus (two observed deaths; SMR 235), rectum (three; SMR 242), liver and biliary tract (two; SMR 225), and lymphatic/ haematopoietic cancer (six; SMR 147). The mortality of the workers in these four pesticide plants was later updated from 1976 to the end of 31 December 1987 by Brown. ${ }^{9}$ In this second follow up study mortality from liver and biliary tract cancer had become significant in the plant manufacturing aldrin, dieldrin, and endrin (five observed; SMR 393 national rates, 510 state rates). The increase in mortality from rectum cancer did not persist in this update as no additional deaths from this cancer were observed during the extended mortality follow up. The earlier reported excess of mortality from oesophageal cancer was not specifically considered in the update and the earlier reported excess in lymphatic/haematopoietic neoplasms had also decreased. A third follow up study included all employees who ever worked in the aldrin, dieldrin, and endrin \\ Correspondence to: \\ Dr G de Jong, Shell \\ 2501 AN Den Haag, The \\ Shell International BV, \\ Netherlands \\ Epidemiology, \\ Netherlands \\ G M H Swaen
}


Table 1 Percentiles and arithmetic means of estimated daily and total aldrin and dieldrin intake in three exposure groups in the period 1954-70

\begin{tabular}{|c|c|c|c|c|c|c|c|}
\hline \multirow[b]{2}{*}{ Group } & \multirow[b]{2}{*}{$n$} & \multirow[b]{2}{*}{ Daily intake $(\mu \mathrm{g})$} & \multicolumn{5}{|c|}{ Total intake (mg) } \\
\hline & & & Mean & P5 & P50 & P95 & $P 99$ \\
\hline Low & 190 & 90 & 88 & 23 & 74 & 178 & 197 \\
\hline Moderate & 190 & 353 & 419 & 216 & 395 & 703 & 718 \\
\hline High & 190 & 1019 & 1704 & 791 & 1380 & 4025 & 5420 \\
\hline
\end{tabular}

$\mathrm{n}=$ number of subjects; low=low exposure group; moderate=moderate exposure group; high=high exposure group. term health effects of occupational exposure to aldrin and dieldrin.

\section{Material and methods}

The cohort that was followed up in this study had already been extensively studied by Jager ${ }^{5}$ and De Jong. ${ }^{3}$ During these investigations 570 exposed workers were identified, for whom job histories were collected. During the 1970s several biological monitoring programmes of the workers were conducted. Biological monitoring consisted of determinations of dieldrin in blood of exposed workers. These determinations, together with the job histories, provided information to assess total intake of aldrin and dieldrin. The workers were then subdivided into three exposure groups on the basis of their total intake of aldrin and dieldrin during employment in the plant. In table 1 the average daily intake and total intake data are given for three exposure groups.

In addition to these three dose groups a stratification was made according to the job that was performed by the individual worker: assistent operator, operator, maintenance worker, or supervisor. The total study population was followed up for mortality until 1 January 1993. For each study subject the population registry of the municipality in which a study subject was presumably residing was contacted. The population registry was requested to provide information on the vital status of the study subject or to provide the address the subject had moved to. If the study subject had moved to another municipality the procedure was repeated until the vital status on 1 January 1993 could be determined. For deceased study subjects the number of the death certificate was also obtained from the population registries. This number is necessary to retrieve the actual cause of death. The causes of death of persons who have died in The Netherlands are stored at the Central Bureau of Statistics. They have been coded by a trained nosologist at the time of death. Therefore it is impossible that the coding of the causes of death has introduced information bias; the causes of death were coded before the commencement and without any knowledge of the research project. Coding was done according to the International Classification of Diseases. The revision was used that was in effect at the time of death. Because of strict privacy considerations in effect in The Netherlands, the data analysis took place in close collaboration with the Central Bureau of Statistics. These procedures have been described elsewhere in more detail. ${ }^{11}$

The follow up in the present study was expanded until 1 January 1993, which added a total number of 1558.74 person-years to the original study.

Expected numbers of deaths for specific diseases were calculated by means of the national age, period, and cause specific mortalities. The observed numbers were divided by the expected number and multiplied by 100 to generate the SMRs. Exact 95\% confidence intervals $(95 \% \mathrm{CIs})$ were calculated by the method described by Ulm. ${ }^{12}$ 
EXPOSURE SITUATION

Aldrin and dieldrin were manufactured at the plant under investigation between 1954 and 1990. The production process involved manufacturing and formulation. In humans aldrin is rapidly transformed to dieldrin. Therefore the biological monitoring programme focused on dieldrin. Manufacturing formulation of dieldrin and aldrin occurred in several plant units located in the middle of a very extensive petrochemical complex.

In the intermediates plant, intermediates were produced from which aldrin and dieldrin were manufactured. The actual manufacturing process for dieldrin and aldrin took place in the dieldrin and aldrin plant. Several changes in the process were put into effect over time. After a serious explosion in 1957 the process was changed to a continuous process. Despite the extensive use of stainless steel the severe corrosive nature of the original manufacturing process caused leakages, spilling solutions containing dieldrin on the floor. Eventually the reactors were replaced by glass lined ones.

In the formulation plant agrochemicals produced in house were mixed diluted or bound, sometimes adding other externally purchased agrochemicals according the specific product specifications and if desired they were formed into granules.

Other plants, which were part of the same insecticide manufacturing complex, included the endrin plant started up in 1956 and the telodrin plant which was in operation from 1961 to 1964.

The route of exposure to aldrin and dieldrin greatly depended on the typical situation. Oral uptake due to splashing on lips and face was rare. Uptake by skin contact was the main exposure route, particularly when handling liquid containing dieldrin. Uptake by inhalation was probably another important exposure route in particular dusty situations. This is confirmed by the fact that when dust masks were used concentrations of dieldrin in blood declined.

In the late 1950 s static air samples were taken. The results indicate that generally speaking the air contained less than $0.25 \mathrm{mg} / \mathrm{m}^{3}$ of aldrin and dieldrin, except in certain high exposure situations such as drum filling operations. In these situations exposures up to 4 $\mathrm{mg} / \mathrm{m}^{3}$ were measured. For all members of the cohort a job description and information on worksite were available. In the past a routine medical surveillance system was in effect, monitoring dieldrin concentrations in blood of most workers in the plants. The dieldrin concentrations in blood combined with information on job and workplace facilitated the classification of workers into broad exposure categories. For each cohort member a total internal dose of dieldrin was calculated based on the subjects' individual dieldrin concentrations in blood or was extrapolated from the dieldrin concentrations in blood from comparable job holders. The relation between the total daily aldrin or dieldrin intake expressed as oral daily dose and the resulting concentration of dieldrin in blood was derived from a human volunteer study. ${ }^{13} 14$ The exact calculation methods have extensively been described by De Jong. ${ }^{3}$

Briefly, the following methods were used: results for dieldrin in blood, measured during the period 1963-70, were available from a total of 343 insecticide plant workers (from the total cohort of 570). From the remaining 227 subjects dieldrin concentrations in blood were not measured. Most of them were employed in the insecticide plant before 1963 .

The relation between the oral intake of dieldrin over time and the resulting concentration of dieldrin in blood was studied in a human volunteer study. Three groups of adult men, each composed of three subjects, ingested daily oral doses of 10,50 , or $211 \mu \mathrm{g}$ of dieldrin (HEOD) each for 18 months. A fourth group of three men acted as controls. From the 18th month to the 24th month the six volunteers given the two highest doses continued to receive dieldrin at those two concentrations ; the daily dose of the $10 \mu \mathrm{g}$ group was increased to $211 \mu \mathrm{g}$ and the control group was also given $211 \mu \mathrm{g}$ dieldrin daily for this six month period. ${ }^{1314}$

An asymptomic relation of the following form was shown to fit the results:

$$
C=A-B e^{-k\left(t_{1}-t_{2}\right)}
$$

in which $C$ is the dieldrin concentration in blood ( $\mathrm{ng} / \mathrm{ml}$ ) attained at time $t^{t}$ assuming a constant daily dieldrin intake $(\mu \mathrm{g})$ from time $t_{0}$ (beginning of exposure) to time $t_{j} ; A$ is the dieldrin concentration in blood attained at the state of equilibrium, by adventitious as well as by voluntary or occupational constant daily intake of dieldrin; $A-B$ is the background dieldrin concentration in blood by adventitious constant daily intake of dieldrin - for example, via the food; $\left(t_{t}-t_{2}\right)$ is the period (days) during which a subject has been daily exposed to dieldrin; $k$ is the first order rate constant for the elimination of dieldrin from the blood (in days); and $e$ is the base number 2.7183 .

Hunter et $a l^{14}$ calculated the following relation between the concentration of dieldrin in blood and the constant daily intake at the state of equilibrium:

$$
P=\frac{A}{0.086}
$$

in which $P$ is the amount of dieldrin ingested daily ( $\mu \mathrm{g}$ ) and $A$ is the dieldrin concentration expressed in $\mathrm{ng} / \mathrm{ml}$.

By substitution of $A$, the form is:

$$
C=P \times 0.086 \times\left(1-e^{-k\left(t_{1}-t_{0}\right)}\right)
$$

However, for the calculation of the daily aldrin + dieldrin intake, the first formula can be applied during a repeated and regular pattern of exposure to aldrin or dieldrin only. Variable exposure patterns may dominate in the occupational situation. Therefore, the blood dieldrin concentration from a previous exposure pattern has to be taken into consideration when calculating the daily intake during a new exposure pattern. Hunter et $a l^{14}$ experimentally determined that elimination of dieldrin from the blood occurs exponentially 
Table 2 End points of the follow up

\begin{tabular}{lrl}
\hline & $n(\%)$ & \\
\hline Alive at 1 January 1993 & 402 & $(70.5)$ \\
Emigrated & 35 & $(6.2)$ \\
Lost to follow up & 15 & $(2.6)$ \\
Deceased & 118 & $(20.7)$ \\
Cause of death missing & 0 & $(0.0)$ \\
Number of person-years at risk & 16297.28 & \\
Total group & 570 & $(100)$ \\
\hline
\end{tabular}

according to the equation:

$$
C=C_{0} \times e^{-k\left(t_{1}-t_{0}\right)}
$$

in which $C_{0}$ is the initial dieldrin concentration in blood (at time $t_{0}$ ); $C$ is the dieldrin concentration in blood at time $t_{i} ;\left(t_{t}-t_{0}\right)$ is the period (days) which has elapsed since exposure to dieldrin was terminated.

The dieldrin concentration in blood measured during a new exposure pattern is the sum of the dieldrin concentration in blood attained by aldrin or dieldrin absorption during this new exposure pattern and the remainder of the dieldrin concentration in blood attained in a previous exposure pattern.

Jager $^{5}$ determined the concentration of dieldrin in the blood of 15 aldrin and dieldrin workers of the insecticide plant in Pernis at intervals during three years after occupational exposure to aldrin and dieldrin was terminated. The average biological half life of dieldrin in blood was 267 days, providing a $k$ value of 0.0026 day $^{-1}$. This value was used for the calculation of the individual daily intake of insecticide workers.

Dieldrin concentrations in the blood of insecticide workers, measured during the period 1963-1970, showed that in most subjects dieldrin in blood reached a steady state seven to 24 months after the beginning of exposure.

The total intake of aldrin and dieldrin for each person was calculated by multiplication of his daily intake in an exposure period, and subsequently by summation of the total intake for each exposure period over the years 1963-70. To compare the total intake of aldrin and dieldrin and the average daily intake of subjects in

Table 3 Causes of death and expected numbers of deaths for the total group of 570 workers exposed to aldrin and dieldrin *

\begin{tabular}{lrrc}
\hline Cause of death & Obs & \multicolumn{1}{c}{ Exp } & \multicolumn{1}{c}{$S M R$ (95\% CI) } \\
\hline All causes & 118 & \multicolumn{1}{c}{156} & $75.6(63$ to 91$)$ \\
Neoplasms & 46 & 47.5 & $96.8(71$ to 129$)$ \\
Cardiovascular disease & 41 & 67.3 & $61.0(44$ to 83$)$ \\
Respiratory disease & 8 & 9.7 & $82.2(35$ to 162$)$ \\
Other diseases & 23 & 31.6 & $72.8(46$ to 109$)$ \\
Stomach & 5 & 5.1 & $98.9(32$ to 231$)$ \\
Large intestine & 2 & 2.7 & $74.2(9$ to 268$)$ \\
Rectum & 6 & 1.5 & $390.4(143$ to 850$)$ \\
Liver & 2 & 0.9 & $225.0(27$ to 813$)$ \\
Pancreas & 3 & 2.2 & $136.7(28$ to 399$)$ \\
Lung cancer & 19 & 19.1 & $99.8(60$ to 156$)$ \\
Prostate & 1 & 2.4 & $41.0(1$ to 229$)$ \\
Bladder & 2 & 1.5 & $130.3(16$ to 471$)$ \\
Multiple myeloma & 1 & 0.6 & $163.9(4$ to 913$)$ \\
Leukaemia & 2 & 1.4 & $140.7(17$ to 508$)$ \\
Unspecified & 2 & 1.8 & $113.7(14$ to 411$)$ \\
Kidney & 1 & 1.2 & $86.1(2$ to 480$)$ \\
\hline
\end{tabular}

* Only causes of death are presented in which an actual death was observed. This gives the false impression that most SMRs for specific cancer types were raised. the three exposure groups, the group arithmetic means as well as the percentiles were calculated for subjects in each exposure group.

For an estimate of a person's daily intake over the period 1954 until 1963, his dieldrin concentrations as measured during 1963 or 1964, if no data were available during 1963, were used. This method was used provided that the person was employed in the same section of the plant before 1963. If the subject had been employed in another section of the plant before 1963, his daily aldrin and dieldrin intake was estimated by using the 50 percentile of the individual intake calculated for subjects who worked in the same plant, with the same job type, and assigned to the same exposure group as the person concerned. The data were derived from the calculations for exposures during 1964 if less than five observation periods were available during 1963.

The personal total intake of dieldrin was estimated by multiplying the calculated and estimated personal daily intake of dieldrin during an exposure period and the number of days during that exposure period, and subsequently by summation of the total results for each exposure period during 1954-70. From these data the individual total intake and average daily aldrin and dieldrin intake could be estimated for each work area, job type, and exposure group.

The observed concentrations of dieldrin in blood of individual workers correlated strongly with the exposure estimates based on environmental samples, job descriptions, and technical process characteristics. It was estimated that the highest exposures occurred in assistants and operators of the formulation plant and in assistants employed in the aldrin and dieldrin plant. The lowest exposures to aldrin and dieldrin were estimated for the maintenance workers, as they worked on decontaminated equipment and for the workers of the intermediates plant, the endrin plant, and the telodrin plant. A total daily intake and cumulative intake was calculated for each cohort member based on his own measurements of dieldrin in blood or from comparable coworkers. The calculated total uptake for all workers ranged from $11 \mathrm{mg}$ to $7.7 \mathrm{~g}$ of dieldrin with an arithmetic mean of $737 \mathrm{mg}$ of dieldrin.

From these dieldrin in blood measurements it was clear that personal exposure was more or less eliminated by 1970 . Exposures after that date were not included in the analysis.

\section{Results}

Table 2 gives the end point distribution of the follow up. The follow up can be considered as successful. Only 15 persons were lost to follow up. The causes of death ascertainment through the Central Bureau of Statistics was also successful. From all 118 deaths the cause of death given on the death certificate could be ascertained.

The total mortality of the exposed group was lower than expected. A total of 118 workers had died compared with an expected number of 156.0 (table 3). The total mortality from cancer was also lower than expected, which was 
Table 4 Cause specific mortality in 570 workers exposed to aldrin and dieldrin in three dose groups

\begin{tabular}{|c|c|c|c|c|c|c|}
\hline \multirow[b]{2}{*}{ Cause of death } & \multicolumn{2}{|l|}{ Low } & \multicolumn{2}{|c|}{ Moderate } & \multicolumn{2}{|c|}{ High } \\
\hline & Obs & SMR $(95 \% C I)$ & Obs & $S M R(95 \% C I)$ & Obs & SMR $(95 \% C I)$ \\
\hline All causes & 32 & $88.0(60.2$ to 124.2$)$ & 38 & $74.2(52.5$ to 101.9$)$ & 48 & $70.2(51.7$ to 93.0$)$ \\
\hline Neoplasms & 13 & $118.9(63.2$ to 203.3$)$ & 16 & $102.1(58.3$ to 165.8$)$ & 17 & $81.4(47.4$ to 130.3$)$ \\
\hline Cardiovascular disease & 11 & 72.2 (36.0 to 129.0$)$ & 14 & $63.7(34.8$ to 106.9$)$ & 16 & $53.3(30.4$ to 86.5$)$ \\
\hline Respiratory disease & 2 & $95.6(10.7$ to 345.0$)$ & 0 & - & 6 & $132.3(48.3$ to 287.9$)$ \\
\hline Other diseases & 6 & $73.8(26.9$ to 160.6$)$ & 8 & $76.6(32.8$ to 150.3$)$ & 9 & $69.2(31.6$ to 131.4$)$ \\
\hline Stomach & 2 & $175.6(19.7$ to 634.0$)$ & 2 & $122.0(13.7$ to 440.6$)$ & 1 & $43.9(0.6$ to 244.0$)$ \\
\hline Large intestine & 0 & - & 0 & - & 2 & $168.5(18.9$ to 608.3$)$ \\
\hline Rectum & 3 & 864.6 (173.8 to 2526.1$)$ & 1 & 200.8 (2.6 to 1117.2$)$ & 2 & 289.0 (32.5 to 1043.5$)$ \\
\hline Liver & 1 & 497.5 (6.5 to 2768.1$)$ & 1 & $339.0(4.4$ to 1886.1$)$ & 0 & - \\
\hline Pancreas & 1 & $198.4(2.6$ to 1103.9$)$ & 0 & - & 2 & 207.7 (23.3 to 749.8$)$ \\
\hline Lung cancer & 5 & $115.9(37.4$ to 270.5$)$ & 8 & 126.5 (54.5 to 249.3 ) & 6 & $71.4(26.1$ to 155.3$)$ \\
\hline Prostate & 0 & - & 1 & $132.1(1.7$ to 735.0$)$ & 0 & - \\
\hline Bladder & 1 & 290.7 (3.8 to 1617.4$)$ & 0 & - & 1 & $144.3(1.9$ to 802.9$)$ \\
\hline Multiple myeloma & 0 & - & 0 & - & 1 & 367.6 \\
\hline Leukaemia & 0 & - & 2 & $420.2(47.2$ to 1517.0$)$ & 0 & - \\
\hline Unspecified & 0 & - & 1 & $173.9(2.3$ to 967.6$)$ & 1 & $128.7(1.7$ to 716.1$)$ \\
\hline Kidney & 0 & - & 0 & - & 1 & $205.3(2.7$ to 1142.5$)$ \\
\hline
\end{tabular}

also the case for mortality from cardiovascular disease and non-malignant respiratory disease. Malignant diseases that were observed in a higher frequency than expected were rectum and liver cancer. Six deaths from rectum cancer were observed compared with an expected number of 1.5 (SMR = 390.4), which was significant. Two deaths from liver cancer were observed compared with an expected number of 0.9 (SMR = 225), which was not significant.

The stratification by dose level did not disclose any indications for a dose-response relation for either of these two causes of death. The greatest excess of mortality from rectum cancer was found in the lowest dose group. One death from liver cancer occurred in the lowest dose group and one in the moderate dose group (table 4).

An analysis by job title disclosed that the deaths from rectum cancer occurred among the operators and assistant operators, but not in the maintenance workers or supervisors (table 5). One operator and one assistant operator died from liver cancer. These distributions are not surprising because these two job titles combined made up $82 \%$ of the total exposed group.

\section{Discussion}

This study was carried out with the aim of collecting additional mortality information on a group of 570 workers that had been exposed to aldrin and dieldrin in the past. An additional period of seven years of follow up was added to the original study. Within this additional period 42 observed deaths were added to the originally observed 76 . Total mortality and mortality from cancer remained lower than expected. Mortality from two cancer sites was higher than expected-that is, rectum and liver cancer. There was no indication of a doseresponse relation for any of these specific cancer sites. In experiments with mice in which dieldrin was given orally an excess of hepatomas was observed. There are no experimental or epidemiological data which suggest an association between exposure to aldrin and dieldrin or other organochlorine pesticides and rectal cancer. ${ }^{15}$

In this epidemiological study two deaths from (primary) liver cancer were observed, which was not significantly different from the expected number. Further analysing these cases, it was found that one death from liver cancer was observed in the low exposure group and the other case in the moderate exposure group (table 4). The medical history of the moderately exposed case of liver cancer was described in the previous study and suggested a nonoccupational cause of liver cancer. ${ }^{3}$ The medical history of the other observed case, in the low exposure group, is unknown. However, the lack

Table 5 Cause specific mortality in 570 workers exposed to aldrin and dieldrin by job title

\begin{tabular}{|c|c|c|c|c|c|c|c|c|}
\hline \multirow[b]{2}{*}{ Cause of death } & \multicolumn{2}{|c|}{ Assistant operator } & \multicolumn{2}{|c|}{ Maintenance workers } & \multicolumn{2}{|c|}{ Operator } & \multicolumn{2}{|c|}{ Supervisor } \\
\hline & Obs & $S M R(95 \% C I)$ & Obs & $S M R(95 \% C I)$ & Obs & $S M R(95 \% C I)$ & Obs & $S M R(95 \% C I)$ \\
\hline All causes & 64 & $96.2(74.1$ to 122.8$)$ & 20 & $81.8(50.0$ to 126.4$)$ & 30 & 50.8 (34.4 to 72.5$)$ & 4 & $67.3(18.1$ to 172.2$)$ \\
\hline Neoplasms & 24 & $124.4(79.7$ to 185.2$)$ & 5 & $64.5(20.8$ to 150.5$)$ & 16 & 85.8 (49.0 to 139.4$)$ & 1 & 55.0 (0.7 to 306.2$)$ \\
\hline Cardiovascular disease & 23 & $76.5(48.5$ to 114.9$)$ & 10 & $95.3(45.6$ to 175.3$)$ & 5 & $20.7(6.7$ to 48.4$)$ & 3 & $115.4(23.2$ to 337.3$)$ \\
\hline Respiratory disease & 8 & $161.7(69.6$ to 318.7$)$ & 0 & - & 0 & - & 0 & - \\
\hline Other diseases & 9 & 73.2 (33.4 to 139.0 ) & 5 & $105.4(34.0$ to 246.1$)$ & 9 & $66.9(30.5$ to 127.1$)$ & 0 & - \\
\hline Stomach & 2 & $85.9(9.6$ to 310.0$)$ & 1 & $128.4(1.7$ to 714.2$)$ & 1 & $56.9(0.7$ to 316.5$)$ & 1 & 520.8 \\
\hline Large intestine & $\overline{1}$ & 88.0 (1.1 to 489.3$)$ & 0 & - & 1 & 97.6 (1.3 to 542.8$)$ & 0 & - \\
\hline Rectum & 2 & 294.1 (33.0 to 1061.9 ) & 0 & - & 4 & $724.6(194.9 \text { to } 1855.2)^{\star}$ & 0 & - \\
\hline Liver & 1 & 276.2 (3.6 to 1537.0$)$ & 0 & - & 1 & 286.5 (3.7 to 1594.2$)$ & 0 & - \\
\hline Pancreas & 2 & $230.4(25.9$ to 831.9$)$ & 0 & - & 1 & $114.2(1.5$ to 635.1$)$ & 0 & - \\
\hline Lung cancer & 11 & $152.0(95.8$ to 272.1$)$ & 2 & $61.0(6.9$ to 220.3$)$ & 6 & $76.9(28.1$ to 167.4$)$ & 0 & - \\
\hline Prostate & 1 & $71.2(0.9$ to 396.3$)$ & 0 & - & 0 & $-\quad-100$ & 0 & - \\
\hline Bladder & 2 & $289.0(32.5$ to 1043.5$)$ & 0 & - & 0 & - & 0 & - \\
\hline Multiple myeloma & 0 & - & 0 & - & 1 & 450.5 (5.9 to 2506.2$)$ & 0 & - \\
\hline Leukaemia & 0 & - & 1 & 446.4 (5.8 to 2483.9 ) & 1 & $166.1(2.2$ to 924.2$)$ & 0 & - \\
\hline Unspecified & 1 & $129.7(1.7$ to 721.6$)$ & 1 & $367.6(4.8$ to 2045.5$)$ & 0 & - & 0 & - \\
\hline Kidney & 1 & 241.5 (3.2 to 1343.9$)$ & 0 & - & 0 & - & 0 & - \\
\hline
\end{tabular}


of a dose-response relation does not point in the direction of a possible causal relation with exposures to aldrin and dieldrin in the plant.

It is not likely that cases of mortality from liver cancer were missed in this study. The causes of death were already coded according to the International Classification of Diseases before the beginning of the study. The ascertainment of causes of death was complete for the deaths observed in the study. There may have been some underreporting of mortality from liver cancer. However, this would have only led to incorrect conclusions if the underreporting in the exposed group was different from that in the total Dutch male population. This is unlikely.

A strong point of this study was the availability of extensive exposure information. Due to the biological monitoring programmes that have been carried out on these workers since 1963, measurements of dieldrin in blood were available for 343 out of the 570 workers under investigation. The calculated or estimated total intake of dieldrin in the cohort had a range from 11 to $7755 \mathrm{mg}$. It was estimated that more than $75 \%$ of the cohort had dieldrin dose rates while exposed which exceeded the assumed human equivalent dose rate corresponding to the lowest positive dose rate for female mice in a cancer bioassay where the observed liver tumour response rate was roughly double the control rate. Furthermore, more than $25 \%$ of the workers' equivalent dose rates exceeded the second highest dose rate for female mice in the same bioassay-a dose rate where the liver tumour rate was nearly triple the control rate. ${ }^{16}$

This mortality update study does not provide support for the carcinogenicity of occupational exposure to aldrin and dieldrin in a cohort of relatively highly exposed workers. Mortality from two cancer sites out of the 25 types that were analysed were raised. The increase in mortality from rectum cancer was significant. However, no indication for a doseresponse was found. Furthermore, there is no experimental evidence that aldrin or dieldrin can cause rectal cancer. Two workers had died from liver cancer; from one it was known that he had a medical history suggestive of a non-occupational risk factor for liver cancer.
The other was classified in the lowest cumulative dose group, which is inconsistent with a dose-response relation. The current study, together with the data from other mortality studies carried out in the cohort of former aldrin and dieldrin manufacturing workers, has not shown any cancer excesses due to occupational exposures to aldrin and dieldrin.

1 Hayes WJ, Laws ER. Handbook of pesticide toxicology. San Diego: Academic Press, 1991.

2 World Health Organisation. Aldrin and dieldrin. Geneva: WHO, International Programme on Chemical Safety (IPCS), 1989. (Environmental Health Criteria 91.)

3 Jong de G. Long term health effects of aldrin and dieldrin. A study of exposure, health effects and mortality of worker engaged in the manufacture and formulation of the insecticides aldrin and dieldrin. Toxicol Lett 1991;(suppl):115-41.

4 Bragt PC, Schuurbiers CJ, Hollander JCTh, Schulting FL, Wolthuis OL. Determination of the retention of inhaled aldrin in man. Rijswijk: Nederlands Organisation of Applied Scientific Research, Medical Laboratory TNO, MBL Scientific Resea

5 Jager KW. Aldrin, dieldrin, endrin, and telodrin: an epidemiological and toxicological study of long term occupational exposure. New York: Elsevier, 1970

6 Walker AIT, Stevenson DE, Robinson J, Thorpe E, Roberts $M$. The toxicology and pharmacodynamics of dieldrin (HEOD): two-year oral exposure of rats and dogs. Toxicol Appl Pharmacol 1969;15:345-73.

7 International Agency for Research on Cancer. Monographs on the evaluation of the carcinogenic risks to humans. Overall ovaluations of carcinogenicity: an updating of IARC monoevaluations of carcinogenicity: an upda
graphs. Vols 1-42. Lyon: IARC, 1987.

8 Ditraglia D, Brown DP, Namekata T, Iverson N. Mortality study of workers employed at organochlorine pesticide manufacturing plants. Scand $\mathcal{F}$ Work Environ Health 1981;7: $140-6$.

9 Brown D. Mortality of workers employed at organochlorine pesticide manufacturing plants. An update. Scand $\mathcal{f}$ Work pesticide manufacturing plants.

10 Amoateng-Adjepong Y, Sathiakumar N, Delzell E, Cole Ph. Mortality among workers at a pesticide manufacturing plant. F Occup Environ Med 1995;37:471-8.

11 Swaen GMH, Meijers JMM, Vliet van C, Sturmans F. De haalbaarheid van retrospektief kohortonderzoek in de arbeidssituatie in Nederland. T Soc Gezondheidsz 1990;68: 457-65.

12 Ulm K. A simple method to calculate the confidence interval of a standardized mortality ratio (SMR). Am 7 Epidemiol 1990;131:373-5.

13 Hunter CG, Robinson J. Pharmacodynamics of dieldrin (HEOD). I. Ingestion by human subjects for 18 months. Arch Environ Health 1967;15:614-26.

14 Hunter CG, Robinson J. Pharmacodynamics of dieldrin (HEOD). II. Ingestion by human subjects for 18 to 24 months, and postexposure for 8 months. Arch Environ Health 1969;18:12-21.

15 International Programme on Chemical Safety. Aldrin and dieldrin. Geneva: World Health Organisation, IPCS, 1989. (Environmental Health Criteria 91.)

16 Sielken JrR, Stevenson DE. Comparisons of human cancer potency projections for dieldrin based on human data with dose based on animal data. In: D'Amato R, Slaga TJ, Farland $\mathrm{WH}$, Henry C, eds. Relevance of animal studies to the evaluation of human cancer risk. Proceedings of the Seventh International Conference on Carcinogenesis and Risk Assessment, December 1990. Austin, Texas: Wiley-Liss, 1992:295319 . 